\title{
FOXM1 is a molecular determinant of the mitogenic and invasive phenotype of anaplastic thyroid carcinoma
}

\author{
Roberto Bellelli, ${ }^{1,2}$, Maria Domenica Castellone ${ }^{1,2}$, Ginesa Garcia-Rostan ${ }^{3}$, \\ Clara Ugolini ${ }^{4}$, Carmelo Nucera ${ }^{5}$, Peter M Sadow ${ }^{6}$, Tito Claudio Nappi, ${ }^{1,2}$, \\ Paolo Salerno ${ }^{1,2}$, Maria Carmela Cantisani ${ }^{1,2}$, Fulvio Basolo ${ }^{4}$, \\ Tomas Alvarez Gago ${ }^{3}$, Giuliana Salvatore ${ }^{7}$ and Massimo Santoro ${ }^{1,2}$
}

\footnotetext{
${ }^{1}$ Dipartimento di Biologia e Patologia Cellulare e Molecolare, 'L. Califano', Universita' Federico II, Napoli, Italy

'Istituto di Endocrinologia ed Oncologia Sperimentale 'G. Salvatore', C.N.R., Napoli, Italy

${ }^{3}$ Institute of Biology and Molecular Genetics, Spanish Research Council, Valladolid University, Valladolid, Spain

${ }^{4}$ Department of Surgery, University of Pisa, Pisa, Italy

${ }^{5}$ Human Thyroid Cancers Preclinical and Translational Research Program, Division of Cancer Biology and Angiogenesis, Harvard Medical School, Center for Vascular Biology Research, Beth Israel Deaconess Medical Center, Boston, Massachusetts, USA

${ }^{6}$ Department of Pathology, Harvard Medical School, Massachusetts General Hospital, Boston, Massachusetts, USA

${ }^{7}$ Dipartimento di Studi delle Istituzioni e dei Sistemi Territoriali, Università Parthenope, Napoli, Italy
}

(Correspondence should be addressed to M Santoro who is now at Dipartimento di Biologia e Patologia Cellulare e Molecolare, University of Naples 'Federico II', Via Pansini 5, 80131 Naples, Italy; Email: masantor@unina.it)

\begin{abstract}
Anaplastic thyroid carcinoma (ATC) is a very aggressive thyroid cancer. forkhead box protein M1 (FOXM1) is a member of the forkhead box family of transcription factors involved in control of cell proliferation, chromosomal stability, angiogenesis, and invasion. Here, we show that FOXM1 is significantly increased in ATCs compared with normal thyroid, well-differentiated thyroid carcinomas (papillary and/or follicular), and poorly differentiated thyroid carcinomas $(P=0.000002)$. Upregulation of FOXM1 levels in ATC cells was mechanistically linked to lossof-function of p53 and to the hyperactivation of the phosphatidylinositol-3-kinase/AKT/FOXO3a pathway. Knockdown of FOXM1 by RNA interference inhibited cell proliferation by arresting cells in $\mathrm{G} 2 / \mathrm{M}$ and reduced cell invasion and motility. This phenotype was associated with decreased expression of FOXM1 target genes, like cyclin B1 (CCNB1), polo-like kinase 1 (PLK1), Aurora B $(A \cup R K B)$, S-phase kinase-associated protein 2 (SKP2), and plasminogen activator, urokinase: UPA (PLAU). Pharmacological inhibition of FOXM1 in an orthotopic mouse model of ATC reduced tumor burden and metastasization. All together, these findings suggest that FOXM1 represents an important player in thyroid cancer progression to the anaplastic phenotype and a potential therapeutic target for this fatal cancer.
\end{abstract}

Endocrine-Related Cancer (2012) 19 695-710

\section{Introduction}

Anaplastic thyroid carcinoma (ATC) is a rare tumor that accounts for $2-5 \%$ of all thyroid cancers. ATC ranks among the most lethal solid malignancies with a mean survival rate of 4-12 months after diagnosis. ATC usually presents between the 6th and the 7th decade of life as a rapidly enlarging neck mass that extends locally and disseminates to regional nodes and distant sites. Multimodal therapy, including surgery, chemotherapy, and radiotherapy, has only limited benefits in the locoregional control of the disease (Kondo et al. 2006, Smallridge et al. 2009).

ATCs share genetic alterations with well-differentiated thyroid carcinoma (WDTC; papillary thyroid carcinoma (PTC) or follicular thyroid carcinoma (FTC)) and poorly differentiated thyroid carcinoma (PDC), namely point mutations in $R A S$ and $B R A F$ (Garcia-Rostan et al. 2003, Nikiforova et al. 2003). Activation of the phosphatidylinositol-3-kinase (PI3K) pathway, with point mutation or gene amplification of 
PIK3CA or AKT and loss of PTEN, is more frequently found in ATCs than in WDTCs (Gimm et al. 2000, Frisk et al. 2002, Garcia-Rostan et al. 2005, Wu et al. 2005, Santarpia et al. 2008, Ricarte-Filho et al. 2009, Saji \& Ringel 2010). Accordingly, intercross of transgenic mice expressing oncogenic Ras with Pten null mice gave rise to highly aggressive ATCs (Miller et al. 2009). Moreover, while WDTCs are rarely associated with Tp53 mutation, ATCs feature Tp53 mutations (67-88\%) or dysfunction (Kondo et al. 2006, Smallridge et al. 2009, Nikiforov \& Nikiforova 2011).

At a variance from WDTC, ATC has a high proliferation rate and marked aneuploidy (Wreesmann et al. 2002). Recently, we identified a gene expression signature associated with this ATC phenotype (Salvatore et al. 2007). This signature included upregulation of forkhead box protein M1 (FOXM1).

FOXM1 is a member of the forkhead box family of transcription factors (Korver et al. 1997). It promotes cell cycle progression by affecting both the G1/S and the G2/M transitions, and it is an important regulator of chromosomal stability (Laoukili et al. 2005). Accordingly, FOXM1 regulates the expression of a large number of $\mathrm{G} 2 / \mathrm{M}$-specific genes, such as cyclin B1 (CCNB1), polo-like kinase 1 ( $P L K 1)$, never in mitosis gene-related kinase 2 (NEK2), and centromere protein $\mathrm{F}(C E N P F)$. Interestingly, most of these genes were part of the ATC signature (Salvatore et al. 2007) and one of them, PLK1, was shown to be a promising therapeutic target for ATC (Nappi et al. 2009). FOXM1 deletion is associated with mitotic spindle defects and cell death through mitotic catastrophe (Wonsey \& Follettie 2005). Compounds, like the antibiotic thiostrepton, targeting FOXM1 induce apoptosis in cancer cell lines, suggesting that FOXM1 may represent a potential therapeutic cancer target (Bhat et al. 2009, Hegde et al. 2011). FOXM1 has also been shown to regulate the transcription of genes involved in angiogenesis and invasion, thus acting as a master regulator of metastasization (Raychaudhuri \& Park 2011). Accordingly, FOXM1 downregulation reduced invasion and migration of pancreatic and breast cancer-derived cell lines (Wang et al. 2007, Ahmad et al. 2010). FOXM1 overexpression has been observed in several human cancers, including glioblastoma (Liu et al. 2006), basal cell (Teh et al. 2002), hepatocellular (Kalinichenko et al. 2004), breast (Wonsey \& Follettie 2005), prostate (Kalin et al. 2006), and gastric (Li et al. 2009) carcinomas, being frequently associated with high proliferative rates, invasive phenotype, and dismal prognosis.
Recently, Ahmed et al. (2012) reported that FOXM1 was upregulated in a fraction $(28.4 \%)$ of PTCs. Moreover, chemical or genetic FOXM1 block reduced PTC cell invasiveness, survival, and metalloproteinase (MMP2 and MMP9) expression levels.

Here, we show that FOXM1 is strongly upregulated in ATCs. We also show that FOXM1 expression in ATC cells is sustained by the PI3K/AKT as well as by the loss-of-function of the p53 pathway. FOXM1 knockdown reduced proliferation, survival, and invasion of ATC cells. Finally, pharmacological inhibition of FOXM1 reduced tumor burden and metastasization in an orthotopic mouse model of ATC. These results suggest that ATC cells are addicted to FOXM1 and that FOXM1 targeting may represent a strategy for the treatment of ATCs.

\section{Materials and methods}

\section{Tissue samples and immunohistochemistry}

Formalin-fixed paraffin-embedded ATC, PDC, and normal thyroid tissue samples (132 cases and 552 tissue cores) for immunohistochemical analysis were retrieved from the files of the Pathology Departments of Hospital Central de Asturias (Oviedo University, Asturias, Spain) and Hospital Clinico Universitario Santiago Compostela (Santiago de Compostela University, Galicia, Spain). An additional group of WDTC (36 PTCs and ten FTCs) tissue samples were retrieved from the files of the Department of Surgery, University of Pisa (Italy). Processing of samples and patient information proceeded in agreement with review board approved protocols. Case selection was based on the histological findings and availability of adequate material for RNA extraction. All histological diagnoses were reviewed by two blinded pathologists (G Garcia-Rostan and C Ugolini) according to the latest recommendations about diagnostic features of PTC, FTC, PDC, and ATC (Hedinger et al. 1989, Volante et al. 2007, Garcia-Rostan \& Sobrinho-Simoes 2011). Twenty-seven percent of the PDCs (21/78) analyzed disclosed intratumoral progression, with concurrent WDTC areas (PTC or FTC in 19 or two samples respectively). Twenty-four percent $(24.4 \%)$ of the ATCs (10/41) featured concurrent PDC (four cases), PTC (three cases), FTC (one case), or PDC and PTC (two cases) areas. Whenever observed, such areas with different degree of differentiation and/or aggressiveness within the same case were individually analyzed. Formalin-fixed and paraffin-embedded 3-5 $\mu$ m-thick tissue microarray (TMA) sections were deparaffinized, placed in a solution of absolute 
methanol and $0.3 \%$ hydrogen peroxide for $30 \mathrm{~min}$, and treated with blocking serum for $20 \mathrm{~min}$. The slides were incubated with rabbit polyclonal anti-FOXM1 antibody (dilution 1:200; H-300, Santa Cruz Biotechnology, Santa Cruz, CA, USA) and processed according to standard procedures. Negative controls by omitting the primary antibody were included. To improve the representativity of the expression analysis, two to six core biopsies of $1 \mathrm{~mm}$ in diameter, from different regions of the same specimen or different blocks of the same tumor, were included in the TMAs. Cases were scored as positive when unequivocal brown staining was observed in the nuclei of tumor cells. Immunoreactivity was expressed as the average percentage of positively stained target cells $(-:$ no staining, $<5 \%$ positive cells; + : low/weak, $\geq 5-\leq 25 \%$ positive cells; ++ : medium/moderate, $>25-<50 \%$ positive cells; +++ : high/strong, $\geq 50$ positive cells). Score values were independently assigned by two blinded investigators ( $\mathrm{G}$ GarciaRostan and C Ugolini) and a consensus was reached on all scores used for computation.

\section{RNA extraction and RT-PCR}

Snap-frozen thyroid tumors and normal thyroid (from patients who underwent neck dissection for other diseases) tissue samples (61 cases) for RNA extraction and RT-PCR were retrieved from the files of the Department of Surgery, University of Pisa (Italy). RNA was isolated using' the RNeasy Kit (Qiagen). The quality of the RNAs was verified by the 2100 Bioanalyzer (Agilent Technologies, Waldbronn, Germany); only samples with RNA integrity number value $>7$ were used for further analysis. RNA $(1 \mu \mathrm{g})$ from each sample was reverse transcribed with the QuantiTect Reverse Transcription (Qiagen). PCR reactions were done in triplicate and fold changes were calculated with the formula: $2^{- \text {(sample } 1 \Delta C \mathrm{t}-\text { sample } 2 \Delta C \mathrm{t})}$, where $\Delta C \mathrm{t}$ is the difference between the amplification fluorescent threshold of the mRNA of interest and the mRNA of RNA polymerase 2 used as an internal reference. Primers and PCR conditions are listed in Supplementary Materials and Methods, see section on supplementary data given at the end of this article.

\section{Cell cultures}

Normal thyroid P5 cells were provided by F Curcio (Università di Udine, Udine, Italy) in 2003. All the other cell lines are derived from primary ATCs. 8505C and CAL62 cells were purchased from Deutsche Sammlung von Mikroorganismen und Zellkulturen
(DSMZ) GmbH, Braunschweig, Germany) in 2006. HTH74 cells were obtained from N E Heldin (University Hospital, Uppsala, Sweden) in 2005. OCUT-2, TTA1, and ACT1 cells were provided by $\mathrm{N}$ Onoda (Osaka University of Medicine, Osaka, Japan) in 2005. All the cells were DNA profiled by short tandem repeat analysis and shown to be unique and identical to those reported in Schweppe et al. (2008). P5 were grown as described previously (Curcio et al. 1994). The thyroid cancer cell lines were grown in DMEM (Invitrogen) containing 10\% fetal bovine serum. LY294002 was from Calbiochem (Merck Chemicals Ltd.) and used at $10 \mu \mathrm{M}$ final concentration. PD98059 was from Cell Signaling (Beverly, MA, USA) and used at $50 \mu \mathrm{M}$ final concentration. Thiostrepton was from Sigma-Aldrich.

\section{Protein studies}

Protein extraction and immunoblotting was carried out according to standard procedures. Anti-FOXM1 antibody (H-300) was from Santa Cruz Biotechnology; anti-cleaved (Asp ${ }^{175}$ ) caspase-3 was from Cell Signaling; anti-poly(ADP-ribose) polymerase (anti-PARP) monoclonal antibody, which detects full-length PARP and the large fragment $(89 \mathrm{kDa})$ produced by caspase cleavage, was from BD Biosciences (San Jose, CA, USA); monoclonal anti- $\alpha$-tubulin was from SigmaAldrich. Secondary anti-mouse and anti-rabbit antibodies coupled to HRP were from Santa Cruz Biotechnology.

\section{Plasmids}

The HA-FOXM1b plasmid was purchased from Origene Technologies (Rockville, MD, USA); HA-FOXM1c was a kind gift of $\operatorname{Dr} \mathrm{K} M$ Yao (University of Hong Kong). Expression vectors for wild-type p53, p53-R248G, p21(CIP1/WAF1) (CDKN1A), E2F1 (1-374), E2F4, wild-type AKT, AKT-K179M, and FOXO3a were used.

\section{RNA interference}

FOXM1 siRNA smart pool was purchased from Dharmacon (Lafayette, CO, USA). The siCONTROL non-targeting pool (\#D-001206-13-05) was used as a negative control. Cells were transfected with $100 \mathrm{nM}$ siRNA using Dharmafect 3 siRNA reagent following manufacturer's instructions.

\section{Invasion assay}

In vitro invasiveness through Matrigel was assayed using transwell cell culture chambers. Briefly, 8505C 
and HTH74 confluent cell monolayers were harvested with trypsin/EDTA and centrifuged at $800 \mathrm{~g}$ for $10 \mathrm{~min}$. The cell suspension $\left(1 \times 10^{5}\right.$ cells/well $)$ was added to the upper chamber of transwells on prehydrated polycarbonate membrane filter of $8 \mu \mathrm{m}$ pore size (Costar, Cambridge, MA, USA) coated with $35 \mu \mathrm{g}$ Matrigel (BD Biosciences). The lower chamber was filled with complete medium. Cell dishes were incubated at $37{ }^{\circ} \mathrm{C}$ in $5 \% \mathrm{CO}_{2}$ and $95 \%$ air for $24 \mathrm{~h}$. Nonmigrating cells on the upper side of the filter were wiped-off and migrating cells on the reverse side of the filter were stained with $0.1 \%$ crystal violet in $20 \%$ methanol for $15 \mathrm{~min}$, counted, and photographed. Cell migration was quantified by counting the number of stained nuclei in five individual fields in each transwell membrane in triplicate. Each experiment was repeated three times.

\section{Wound healing assay}

8505C and HTH74 cells were grown up to $80 \%$ confluence; a wound of $\sim 300 \mu \mathrm{m}$ width was inflicted to the cell monolayer with a sterile pipette tip. The culture medium was changed to remove nonadherent cells. The progress of wound closure (healing) was monitored and microphotographs of $\times 10$ magnification were taken immediately and $24 \mathrm{~h}$ after the wound. Pixel densities in the wound areas were measured using the Cella Software (Olympus Biosystem $\mathrm{GmbH}$, Hamburg, Germany) and expressed as percentage of wound closure. The experiment was repeated three times.

\section{Luciferase assay}

Cells were transfected with $500 \mathrm{ng}$ of the reporter plasmid DNA (6XCDX2), together with the other required plasmids, using Lipofectamine reagent (Invitrogen) according to manufacturer's instructions. A plasmid expressing the enzyme Renilla luciferase (pRL-null) was used as internal control. In all cases, the total amount of transfected plasmid DNA was normalized by adding empty vector DNA. Forty-eight hours after transfection, Firefly and Renilla luciferase activities were assayed using the Dual-Luciferase Reporter System (Promega Corporation), and the Lumat LB9507 luminometer (EG Berthold, Bad Wildbad, Germany). Each experiment was done in triplicate.

\section{Fluorescence-activated cell sorter analysis}

Cells were harvested and fixed in $70 \%$ ethanol for $4 \mathrm{~h}$. After washing with PBS, cells were treated with RNase A (100 units $/ \mathrm{ml})$ and stained with propidium iodide
(25 $\mu \mathrm{g} / \mathrm{ml}$; Sigma-Aldrich) for $30 \mathrm{~min}$. Samples were analyzed with an FACS-CyAN interfaced with the Summit V4.2 Software (Dako, Glostrup, Denmark). Data were analyzed with the Modfit Software (Verity Software House, Topsham, ME, USA).

\section{Orthotopic tumor experiments}

Mice experiments were done in the Division of Cancer Biology and Angiogenesis (Program: Human Thyroid Cancers Preclinical and Translational Research) at the Beth Israel Deaconess Medical Center (Boston, MA) in accordance with federal, local, and institutional guidelines. We used an orthotopic mouse model of ATC as described previously (Nucera et al. 2009, 2010, 2011). Eight mice (4- to 6-week-old severe combined immunodeficient - SCID ICR - female mice, Taconic, USA) were injected in the right mouse thyroid lobe with 8505c ATC cells and randomly divided into two groups (vehicle or thiostrepton) of four mice each. Thiostrepton was dissolved at a concentration of $50 \mathrm{mg} / \mathrm{ml}$ in $1 \%$ dimethyl sulfoxide (DMSO) in PBS and the drug solution was sonicated for $10 \mathrm{~min}$. Mice were treated by i.p. injection with $500 \mathrm{mg} / \mathrm{kg}$ body weight per day of thiostrepton or with vehicle using a Hamilton syringe, twice a week for 3 weeks starting 7 days after orthotopic tumor implantation (early therapeutic intervention model). Thiostrepton-treated mice compared to vehicle-treated mice displayed signs of toxicity in the third week of treatment (e.g. 1.2-fold decrease in body weight and piloerection). Mice were killed and tissue specimens were fixed with $10 \%$ buffered formalin phosphate and embedded in paraffin blocks. Histopathology evaluation was performed by an endocrine pathologist (PM Sadow, MGH, Harvard Medical School, Boston) on hematoxylin and eosin (H\&E)stained tissue sections of the orthotopic thyroid tumors, the surrounding perithyroidal tissues, and the lungs. Slides were examined with an Olympus BX41 microscope and the Olympus Q COLOR 5 photo camera (Olympus, Center Valley, PA, USA). For each mouse, the number of metastases was counted as the number of pleomorphic 8505 c cells foci/section of whole lung. The number of metastases found in each mouse was averaged per each group.

\section{Statistical analysis}

The two-tailed unpaired Student's $t$-test was used for statistical analysis. All $P$ values were two sided and differences were significant when $P$ was $<0.05$. All statistical analysis was carried out using the GraphPad Instat Software program (version 3.06.3; GraphPad, San Diego, CA, USA). 


\section{Results}

\section{Increased FOXM1 expression in ATC}

We studied the expression of FOXM1 by immunohistochemistry in a set of 13 normal thyroids, 78 PDCs, and 41 ATCs. Results are reported in Table 1 and representative pictures are shown in Fig. 1. FOXM1 was not detectable in normal thyroid samples. Overall, 45 and $90 \%$ of the PDCs and ATCs respectively expressed FOXM1 $(P=0.0000011$ two-tailed Fisher's exact test; relative risk $(\mathrm{RR})=0.16$; $95 \%$ confidence interval (95\% CI), 0.063-0.434). High $(+++)$ and/or medium $(++)$ levels of FOXM1 immunoreactivity significantly correlated with the ATC phenotype (17 vs $65 \%$ of positively stained PDCs and ATCs respectively; $P=0.000045$ Fisher's exact test; $\chi^{2}$ Yates value 14.95, $P=0.00011$ and $\chi^{2}$ Pearson value 16.85 , $P<0.0001 ; \mathrm{RR}=2.58 ; 95 \% \mathrm{CI}, 1.59-4.20$; Table 1 and Fig. 1). In a very small set of distant metastases of PDC cases to the brain or lung (three cases), we observed that those metastases that exhibited a PDC phenotype expressed FOXM1 (30-50\% of the cells) while the metastasis displaying a phenotype (FTC) that was better differentiated than the primary tumor (PDC) was negative for FOXM1 (Supplementary Figure 1, see section on supplementary data given at the end of this article).

Thirty-one out of 119 PDC and ATC cases presented concurrent areas displaying more prominent differentiated features than the rest of the tumor (see Table 2). In 11 (35.5\%) of these cases, FOXM1 expression was restricted to the PDC or ATC areas (Table 2). Twenty-one percent (5/24) of the concurrent PTC foci present in the PDCs and ATCs analyzed displayed low immunoreactivity $(\geq 5-\leq 25 \%$ positive cells) and none showed moderate or high staining levels (Table 2). This figure is consistent with a recent report by Ahmed et al. (2012), who reported FOXM1 expression in $28.4 \%$ of PTC. Finally, none of the concurrent FTC foci (n. 3) present in the PDCs and ATCs analyzed expressed FOXM1.

Then, we selected a group of additional WDTCs (FTCs and PTCs) for further analysis. In particular, we selected PTCs belonging to different subtypes and that have infiltrated or not tumor or thyroid capsule. As shown in Supplementary (Table 1), see section on supplementary data given at the end of this article, both FTCs and PTCs resulted negative or disclosed low $(+)$ FOXM1 expression levels. PTC stain for FOXM1 depended on the specific variant analyzed. According to Ahmed et al. (2012), tall-cell variant PTC as well as PTCs with tall-cell areas featured increased positivity compared with the other PTC variants $(P=0.027$ Fisher's exact test; $\chi^{2}$ Yates value $4.71, P=0.029$ and $\chi^{2}$ Pearson value $6.41, P=0.011 ; \mathrm{RR}=1.77 ; 95 \% \mathrm{CI}$, 1.08-2.90). Moreover, a significant correlation was found between FOXM1 expression and tumor $(P=0.017$ Fisher's exact test $)$ or thyroid $(P=0.0045$ Fisher's exact test; $\chi^{2}$ Yates value $7.71, P=0.005$ and $\chi^{2}$ Pearson value $9.75, P=0.001 ; \mathrm{RR}=2.28 ; 95 \% \mathrm{CI}$, $1.25-4.17)$ capsule invasion. Instead, no correlation was found between FOXMI expression and the presence of lymph node metastases from primary PTCs $(P=0.30$ Fisher's exact test; Supplementary Table 2, see section on supplementary data given at the end of this article). Even when considering selected cases of WDTCs (with a high percentage of infiltrating tumors), we observed that FOXM1 was significantly increased in ATCs compared with WDTCs (PTCs + FTCs; $P=0.000003)$, PTCs $(P=0.0001)$, and FTCs $(P=0.00002)$.

We performed qRT-PCR analysis on RNA extracted from normal thyroids ( 16 cases), PTCs (19 cases), PDC (11 cases), and ATCs (15 cases). FOXM1 mRNA expression was significantly higher in ATC samples compared with normal thyroid $(P<0.001)$, PTCs $(P<0.001)$, and PDCs $(P<0.001$; Fig. 2A).

Table 1 FOXM1 expression by immunohistochemistry in poorly differentiated thyroid carcinoma (PDC) and anaplastic thyroid carcinoma (ATC)

Number of cases in each category (percentage of stained target cells)

\begin{tabular}{|c|c|c|c|c|}
\hline \multirow[b]{2}{*}{ Sample diagnosis } & \\
\hline & Negative $(-)$ & Low/weak $(+)$ & $\begin{array}{c}\text { Medium/moderate } \\
\qquad(++)\end{array}$ & High/strong $(+++)$ \\
\hline Normal thyroid (13 cases) & $13(100 \%)$ & $0(0 \%)$ & $0(0 \%)$ & $0(0 \%)$ \\
\hline PDC (78 cases-347 cores) ${ }^{a}$ & $43(55.1 \%)$ & $29(37.2 \%)$ & $6(7.7 \%)$ & $0(0 \%)$ \\
\hline ATC $\left(41\right.$ cases -192 cores) ${ }^{a}$ & $4(9.7 \%)$ & $13(31.7 \%)$ & $12(29.3 \%)$ & $12(29.3 \%)$ \\
\hline
\end{tabular}

,$-<5 \%$ of cells positive for nuclear FOXM1 expression;,$+ \geq 5-\leq 25 \%$ of cells positive for nuclear FOXM1 expression; ,$++>25-<50 \%$ of cells positive for nuclear FOXM1 expression;,$+++ \geq 50 \%$ of cells positive for nuclear FOXM1 expression. a To improve the representativity of the expression analysis, two to six core biopsies of $1 \mathrm{~mm}$ in diameter, from different regions of the same specimen or different blocks of the same tumor, were included in the TMAs. 


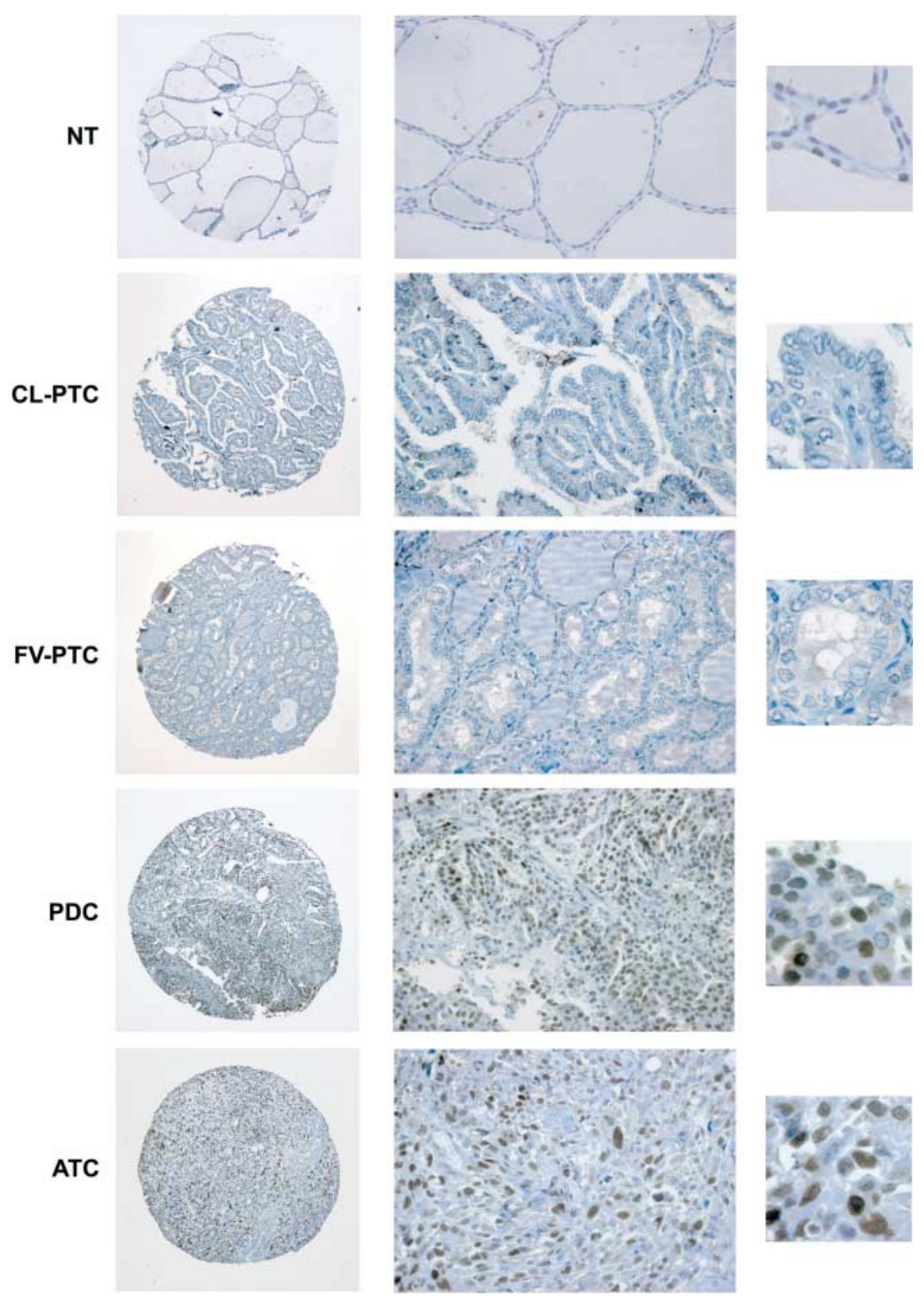

Figure 1 Immunohistochemical analysis of FOXM1 expression in human thyroid tissue samples. Representative images of normal thyroid (NT), classic variant-PTC (CL-PTC), follicular variant-PTC (FV-PTC), PDC, and ATC biopsies stained with a rabbit polyclonal anti-FOXM1 antibody. Whole tissue cores (left, 10X) and zoom-in of areas present within these particular cores (center, $40 \times$ and right, $100 \times$ ), illustrating the nuclear features and FOXM1 staining pattern, are shown. The NT, CL-PTC, and FV-PTC sections are negative for FOXM1, whereas the PDC and ATC sections disclose diffuse, medium/moderate $(++)$, and high/ strong $(+++)$ nuclear immunoreactivity respectively.

FOXM1 gene is located on chromosome 12p13.3 and consists of nine exons, two of which (A1 and A2) are alternatively spliced giving rise to three differentially expressed forms: FOXM1a (containing both A1 and A2 exons), FOXM1c (containing only A1), and FOXM1b (lacking both A1 and A2) (Fig. 2B). Only FOXM1b and FOXM1c are active as transcription factors because of the lack of the inhibitory sequence encoded by exon A2 (Ye et al. 1997). To address the relative expression of the three forms in normal and tumor thyroid tissues (nine samples for each category), we applied RT-PCR and primers specifically designed to amplify the regions containing A1 and A2 exons. These primers generate large or small PCR fragments depending on the presence or not of the targeted exon. In particular, to discriminate between FOXM1a and FOXM1b and $c$, we used a primer pair (F3 and R3) that produced PCR 
Table 2 FOXM1 expression in concurrent differentiated thyroid carcinoma foci present within PDCs and ATCs

\begin{tabular}{|c|c|c|}
\hline \multirow[b]{2}{*}{ Patient number } & \multicolumn{2}{|c|}{ FOXM1 staining score ${ }^{a}$} \\
\hline & Concurrent WDTC component & Prevailing PDC/ATC component \\
\hline 1 & $(-)$ FV-PTC & $(-)$ PDC \\
\hline 2 & $(-)$ FV-PTC & $(-)$ PDC \\
\hline 3 & $(-)$ FV-PTC & $(+)$ PDC \\
\hline 4 & $(+)$ CL-PTC & $(+)$ PDC \\
\hline 5 & $(+)$ FV-PTC & $(+)$ PDC \\
\hline 6 & $(-)$ FTC & $(+)$ PDC \\
\hline 7 & $(-)$ FV-PTC & $(-)$ PDC \\
\hline 8 & (-) CL-PTC with focal tall-cell features & $(-)$ PDC \\
\hline 9 & $(-)$ FV-PTC & $(-)$ PDC \\
\hline 10 & $(-)$ TCV-PTC & $(-)$ PDC \\
\hline 11 & $(-)$ FV-PTC & $(+)$ PDC \\
\hline 12 & $(-)$ FTC Hürthle & $(+)$ PDC \\
\hline 13 & $(-)$ FV-PTC & $(-)$ PDC \\
\hline 14 & (-) Solid PTC & $(+)$ PDC \\
\hline 15 & $(-)$ FV-PTC & $(-)$ PDC \\
\hline 16 & $(+)$ Mixed-PTC with focal tall-cell features & $(+)$ PDC \\
\hline 17 & (-) CL-PTC with focal tall-cell features & $(+)$ PDC \\
\hline 18 & (-) Solid PTC & $(-)$ PDC \\
\hline 19 & $(-)$ FV-PTC & $(-)$ PDC \\
\hline 20 & $(-)$ FV-PTC & $(-)$ PDC \\
\hline 21 & $(-)$ FV-PTC & $(-)$ PDC \\
\hline 22 & $(-)$ FV-PTC & $(+)$ ATC \\
\hline 23 & $(-)$ FV-PTC & $(+)$ ATC \\
\hline 24 & $(+)$ PDC & $(+)$ ATC \\
\hline 25 & $(+)$ PDC & $(+)$ ATC \\
\hline 26 & (+) TCV-PTC progressing to PDC & $(+)$ ATC \\
\hline 27 & $(-)$ FV-PTC & $(+++)$ ATC \\
\hline 28 & $(-)$ PDC & $(++)$ ATC \\
\hline 29 & $(+)$ FV-PTC & $(+++)$ ATC \\
\hline 30 & $(-)$ FTC Hürthle & $(+++)$ ATC \\
\hline 31 & $(++)$ PDC & $(++)$ ATC \\
\hline
\end{tabular}

The concurrent better differentiated thyroid carcinoma components present within poorly differentiated thyroid carcinomas (PDCs) and anaplastic thyroid carcinomas (ATCs) included well-differentiated follicular thyroid carcinoma (FTC), follicular variant of papillary thyroid carcinoma (FV-PTC), classic papillary thyroid carcinoma (CL-PTC), mixed papillary thyroid carcinoma (FV-PTC + CL-PTC), solid PTC, and tall-cell variant of PTC (TCV-PTC).

ascore is reported as in Table 1.

fragments of 472 and 358 bp respectively depending on the presence of exon A2 (variant FOXM1a); to discriminate between FOXM1b and FOXM1 $a$ and $c$ variants, we used primers (F2 and R2) that produced PCR fragments of 481 and $436 \mathrm{bp}$ respectively depending on the presence of exon A1 (variants FOXM1a and $c$; Fig. 2B). FOXM1b and FOXM1c plasmids were used to generate PCR products as molecular weight controls. Tumor samples predominantly expressed FOXMIC (Fig. 2C). Noteworthy, FOXM1C was reported to be the variant that more strongly triggers proliferation and invasion of cancer cells (Kim et al. 2006). According to the qRT-PCR data, FOXM1 expression in ATC was more prominent and consistent than in PTC and PDC.

\section{Deregulation of the p53 and PI3K pathways promotes FOXM1 overexpression in ATC cells}

We investigated mRNA and protein levels of FOXM1 in a panel of ATC cell lines. A primary culture of normal thyrocytes, P5, was used as control. ATC cell lines expressed high levels of FOXM1 mRNA (Fig. 3A) and protein (Fig. 3B) compared with normal cells. As for tissue samples, ATC cell lines expressed FOXM1c form (Fig. 3A).

Then, we searched for ATC-associated molecular pathways that may trigger FOXM1 upregulation. FOXM1 has been recently identified as a target of p53-mediated repression, secondary to p21(CIP1/WAF1)-mediated $\mathrm{Rb}$ dephosphorylation and E2F 


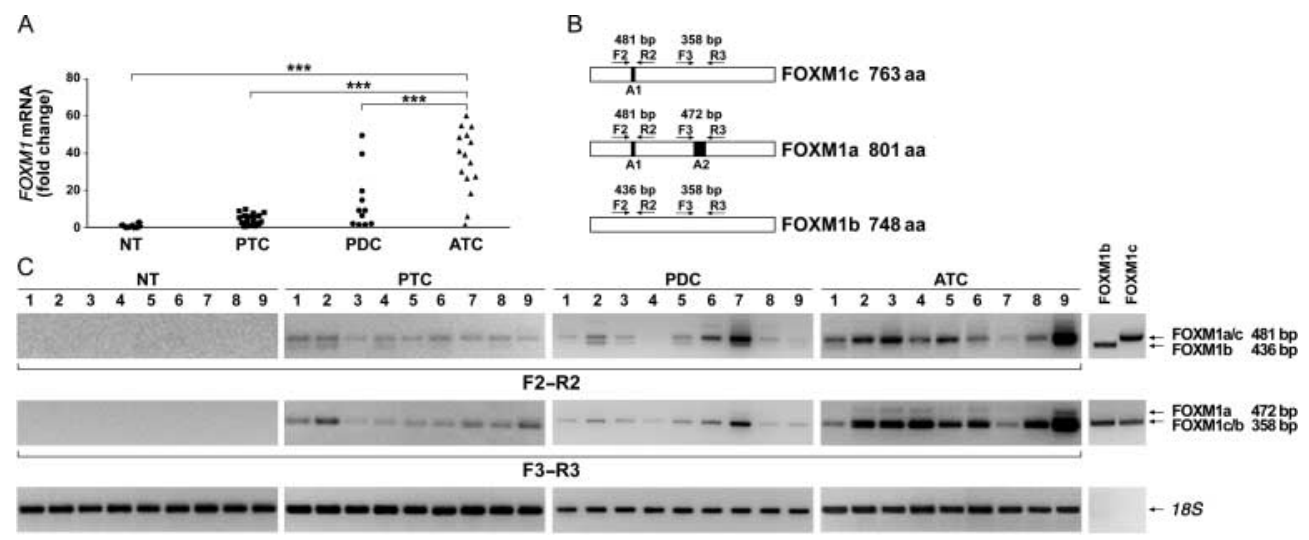

Figure 2 FOXM1 is overexpressed at the mRNA level in human anaplastic thyroid carcinoma samples. (A) Quantitative RT-PCR showing increased FOXM1 expression in ATC (15 cases) compared with normal thyroid (16 cases), PTC (19 cases), and PDC (11 cases) samples. Tumor expression values are reported as fold changes with respect to the average expression in normal samples measured with $\Delta$ Ct method, after normalization for RNA polymerase $2\left({ }^{\star \star \star} P<0.001\right)$. (B) Schematic representation of the three alternatively spliced FOXM1 variants $(a, b$, and $c)$ and the PCR primers used to detect the presence of alternatively spliced exons $\mathrm{A} 1$ and $\mathrm{A} 2$. (C) RT-PCR to show relative expression levels of the three FOXM1 forms in normal thyroids, PTCs, PDCs, and ATCs (nine samples for each category). Plasmids encoding FOXM1b and FOXM1c were used as PCR templates to generate molecular weight controls for the presence or the absence of exon A1 (primers F2/R2) or exon A2 (primers F3/R3). Arrows indicate expected migration for PCR products containing (variants FOXM1a and FOXM1c) or lacking (FOXM1b) exon A1 and for PCR products containing (FOXM1a) or lacking (FOXM1b and FOXM1C) exon A2. The molecular weight of the PCR products is shown on the right. Levels of $18 S$ rRNA were measured for normalization.

downregulation (Barsotti \& Prives 2009, Pandit et al. 2009). This event is critical for the maintenance of a stable G2 arrest in response to DNA damage. Thus, we transfected two ATC-derived cell lines, 8505C and HTH74, both harboring TP53 point mutations (R248G and $\mathrm{K} 286 \mathrm{E}$ respectively) with plasmids coding for wild-type p53, p53-R248G (inactive mutant), p21(CIP1/WAF1), E2F1(1-374) (a dominant negative $\mathrm{E} 2 \mathrm{~F} 1$ ), and E2F4 (a negative regulator of the E2F family) together with a firefly luciferase reporter (6XCDX2) that contains FOXM1 binding sites and therefore is able to monitor FOXM1 transcriptional activity (Kim et al. 2006). As shown in Fig. 4A, adoptive overexpression of p53 wt, p21(CIP1/WAF1), E2F1(1-374), and E2F4 decreased FOXM1 activity, compared with cells transfected with the empty vector $(P<0.001)$, while $\mathrm{p} 53-\mathrm{R} 248 \mathrm{G}$ did not show any significant effect (Fig. 4A). Consistently, FOXM1 mRNA levels, as measured by qRT-PCR, were reduced in p53 wt-, p21(CIP1/WAF1)-, and E2F4-transfected cells (Fig. 4B).

Thyroid cancer often features constitutive activation of the PI3K/AKT pathway (Garcia-Rostan et al. 2005, Saji \& Ringel 2010) and this event is more prevalent in ATC than in WDTC (Gimm et al. 2000, Garcia-Rostan et al. 2005, Saji \& Ringel 2010). FOXO3a transcription factor is negatively controlled by AKT and, in turn, FOXM1 gene expression is negatively regulated by FOXO3a in breast cancer (McGovern et al. 2009).
Thus, we transfected ATC cells with plasmids coding for a dominant negative $A K T$ mutant (K179M), wildtype AKT (used as a control), and FOXO3a together with the FOXM1 activity reporter. AKT (K179M) and FOXO3a transfection strongly reduced FOXM1 activity in ATC cells, while wild-type AKT showed no significant effect (Fig. 4A). Accordingly, treatment with LY294002, a chemical PI3K inhibitor, reduced FOXM1-responsive reporter (Fig. 4A) and FOXM1 mRNA levels (Fig. 4B). Importantly, chemical blockade of the MAPK pathway by the MEK1 inhibitor PD98059 did not recapitulate this event (Fig. 4A).

Based on these findings, we correlated protein expression levels of FOXM1 with those of p53 (an indirect marker suggestive of p53 pathway inactivation), phospho-AKT (pSer473), and pERK (Thr202/Tyr204) by immunohistochemical stain of the ATC/PDC TMAs. In summary, among 41 ATC samples, four scored negative and 37 scored positive for FOXM1; one scored negative and 40 scored positive for pAKT; ten scored negative and 31 scored positive for $\mathrm{p} 53$; and 26 scored negative and 15 scored positive for pERK. Among PDC samples, 43 scored negative and 35 scored positive for FOXM1; six scored negative and 72 scored positive for pAKT; 44 scored negative and 34 scored positive for $\mathrm{p} 53$; and 48 scored negative and 30 scored positive for pERK. By applying linear regression analysis, a 

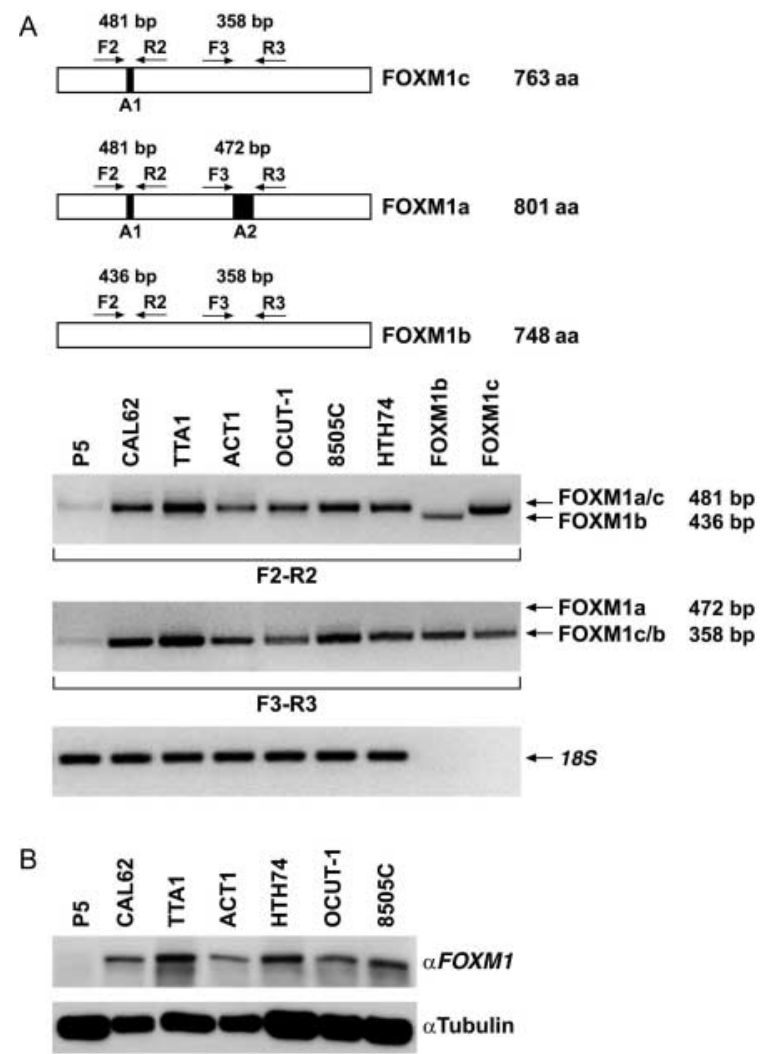

Figure 3 FOXM1 is overexpressed at the mRNA and protein level in ATC cells. (A) Semiquantitative RT-PCR showing increased levels of FOXM1c in ATC cells compared with normal thyrocytes (P5; see legend to Fig. 2). Levels of $18 \mathrm{~S}$ rRNA were measured for normalization. (B) Western blot analysis showing increased protein expression of FOXM1 in ATC cells compared with P5 control. Tubulin was used for normalization. These results are representative of at least three independent experiments.

correlation was found between FOXM1 expression and p53 $(P=0.005$; Pearson correlation coefficient $(\rho) 0.254)$ or pAKT $(P=0.0015$; Pearson correlation coefficient $(\rho)$ 0.286) stain but not between FOXM1 and pERK $(P=0.2)$ stain. All together, these findings suggest that loss of p53 and gain of AKT pathways are molecular events driving FOXM1 transcription levels in thyroid cancer.

\section{Downregulation of FOXM1 inhibited ATC cell growth and invasion in vitro}

We knocked down FOXM1 expression by siRNA in 8505C and HTH74 and monitored cell counts in triplicate at $48 \mathrm{~h}$. FOXMl siRNA but not negative control caused growth inhibition in both cell lines tested $(P<0.001$; Fig. 5A), parallel to FOXM1 mRNA knockdown (see below Fig. 5D). This effect was associated with a reduced $\mathrm{S}$ phase entry $(P<0.05)$ as well as an accumulation of the cells in the G2 phase of the cell cycle $(P<0.05)$ as shown by FACS analysis (Fig. 5A).
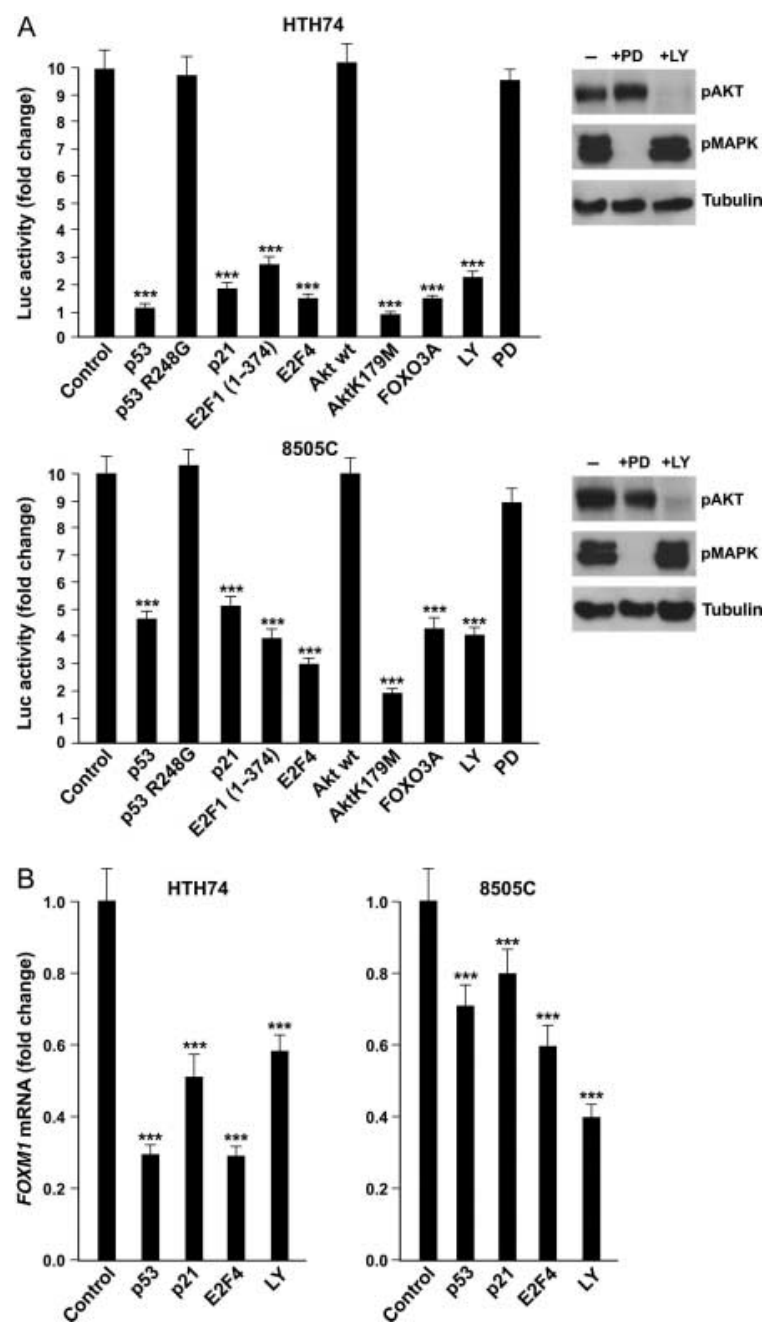

Figure 4 FOXM1 in ATC cells is controlled by the p53 and PI3K pathways. (A) The indicated ATC cells were co-transfected with the indicated expression vectors (or the empty vector as control) together with 6XCDX2 containing six copies of the FOXM1 binding site fused to firefly luciferase. Alternatively, as indicated, cells were treated for $48 \mathrm{~h}$ with the PI3K inhibitor LY294002 or the MEK1 inhibitor PD98059. Cells were co-transfected with Renilla luciferase for normalization. Normalized luciferase levels are reported as average results of three independent experiments with bars illustrating 95\% confidence intervals. Reporter activity in empty vectortransfected cells was arbitrary set at $10\left({ }^{* \star \star} P<0.001\right)$. Western blot analysis of AKT and MAPK phosphorylation after PD98059 and LY294002 treatment is shown on the right. (B) FOXM1 mRNA expression levels were measured in the indicated ATC cells $72 \mathrm{~h}$ after transfection with the indicated plasmids or treatment with LY294002. The average results of three independent experiments are reported together with 95\% confidence intervals. FOXM1 expression in mock-transfected cells was arbitrary set at $1.0\left({ }^{* \star *} P<0.001\right)$. 

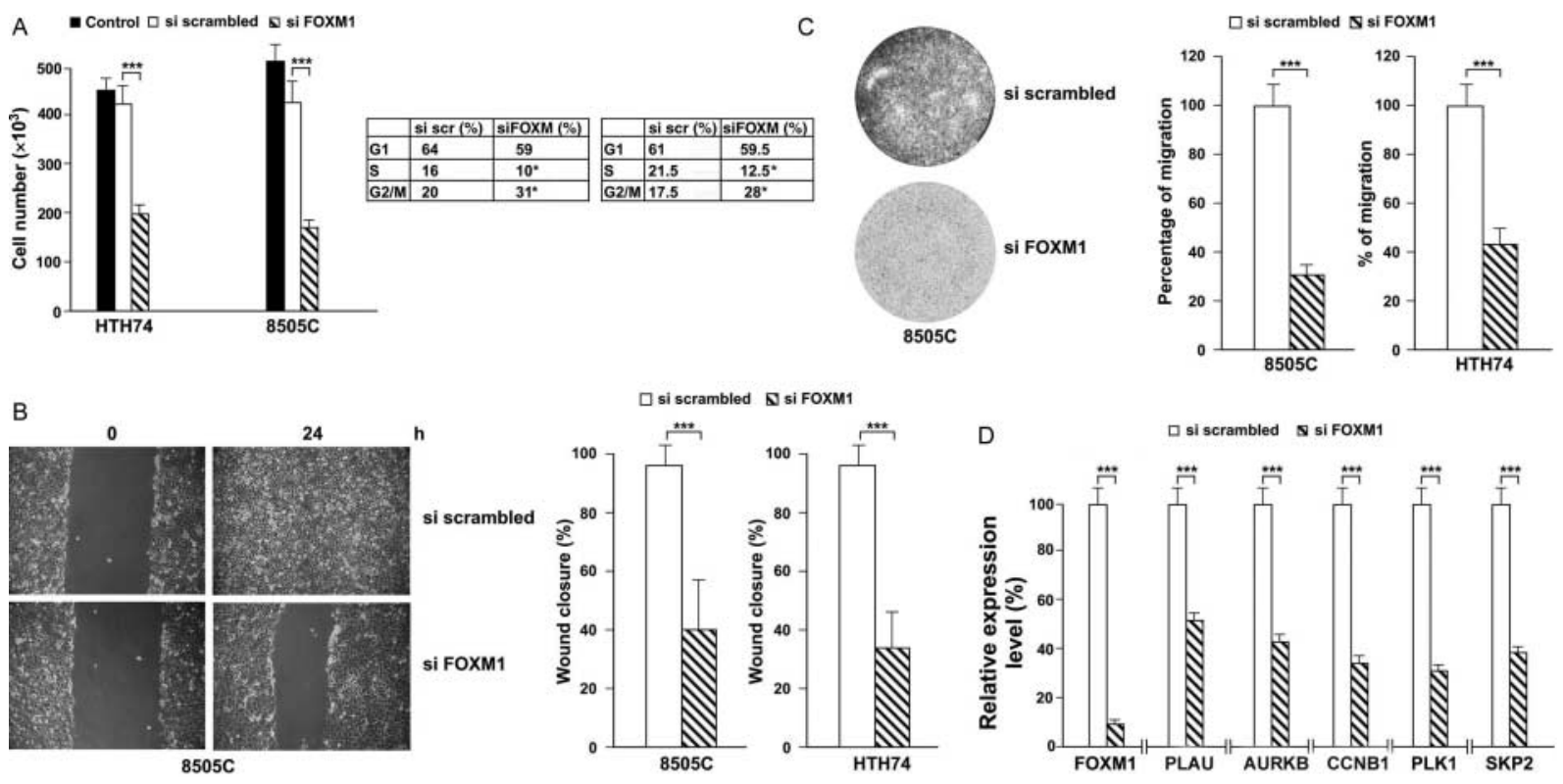

Figure 5 Effect of FOXM1 silencing on ATC cell growth, migration, and invasion. (A) ATC cells were transfected with either FOXM1 siRNA or the negative control siRNA or left untransfected. Cells were harvested at $48 \mathrm{~h}$ and counted. Values represent the average of triplicate experiments with bars indicating $95 \%$ confidence intervals ${ }^{* \star \star} P<0.001$ ). FACS analysis of siFOXM1 or negative control (siSCR)-transfected $8505 \mathrm{c}$ and HTH74 cells is shown together with the mean percentage of cells in G1, S, and G2/M cell cycle phases. Values represent the average of triplicate experiments $\left({ }^{\star} P<0.05\right)$. (B) $8505 \mathrm{C}$ and $\mathrm{HTH} 74$ cells, transfected with either FOXM1 siRNA or the negative control, were plated at confluence and scratch wounds were inflicted. Cell plates were photographed immediately after wound incision and $24 \mathrm{~h}$ later. Photographs were taken at $10 \times$ magnification. Pixel densities in the wound areas were measured and expressed as percentage of wound closure, where $100 \%$ is the value obtained at $10 \mathrm{~h}$ for control cells. The average results of three experiments are reported with bars representing $95 \%$ confidence intervals $\left({ }^{* \star *} P<0.001\right)$. (C) $8505 \mathrm{C}$ and HTH74 cells, transfected with either FOXM1 siRNA or the negative control, were plated in transwells coated with Matrigel. Migration through Matrigel was measured by staining migrated cells with Giemsa. The average results of three experiments are reported with bars representing $95 \%$ confidence intervals $\left({ }^{\star \star \star} P<0.001\right)$. D) RNA was extracted from $8505 \mathrm{C}$ cells, transfected with either $F O X M 1$ siRNA or the negative control, and quantitative RT-PCR assays were performed to detect expression levels of the indicated mRNAs. Levels of actin were measured for normalization.

ATC features a highly invasive and metastatic phenotype. FOXM1 promotes the transcription of genes involved in extracellular matrix degradation and motility, thereby acting as a master regulator of metastasization (Raychaudhuri \& Park 2011). Thus, we monitored cell motility (wound closure assay) and invasion (transwell chamber assay) upon FOXM1 knockdown. FOXM1 depletion significantly impaired the capability of ATC cells (8505c and HTH74) to close the wound $(P<0.001$; Fig. 5B) and to invade through Matrigel $(P<0.001$; Fig. 5C) when compared to the scrambled control.

Finally, we tested whether pro-mitogenic and -invasive effects were mediated by the transcriptional program induced by FOXM1. Transcriptional effects of FOXM1 include upregulation of genes involved in cell proliferation and invasion (Laoukili et al. 2005). As shown in Fig. 5D, FOXM1 downregulation in ATC cells blunted the expression of mRNAs related to cell cycle as well as invasion such as CCNB1, PLK1, $A U R K B, S K P 2$, and PLAU. Noteworthy, some of these
FOXM1 targets have been previously reported to be upregulated in ATC (SKP2, Chiappetta et al. (2007); $C C N B 1$, Ito et al. (2002); AURKB, Sorrentino et al. (2005) and Wiseman et al. (2007); and PLK1, Nappi et al. (2009)).

\section{Pharmacological inhibition of FOXM1-reduced growth and metastasization of ATC cells in an orthotopic mouse model}

FOXM1 has been recently considered as a potential therapeutic target for cancer treatment, thanks to the discovery of a group of compounds able to bind it and inhibit its transcriptional activity (Bhat et al. 2009). Owing to the breakage of a FOXM1-dependent positive feedback loop, these drugs lead to FOXM1 protein reduction and cell death due to apoptosis (Halasi \& Gartel 2009). We first tested whether thiostrepton, the most characterized among them (Radhakrishnan et al. 2006, Kwok et al. 2008, Hegde et al. 2011), was effective at reducing FOXM1 transcriptional activity and protein level in ATC 
A

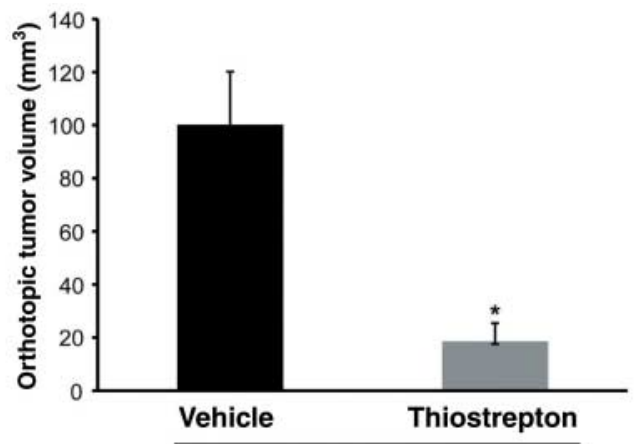

35 Days post tumor implantaion
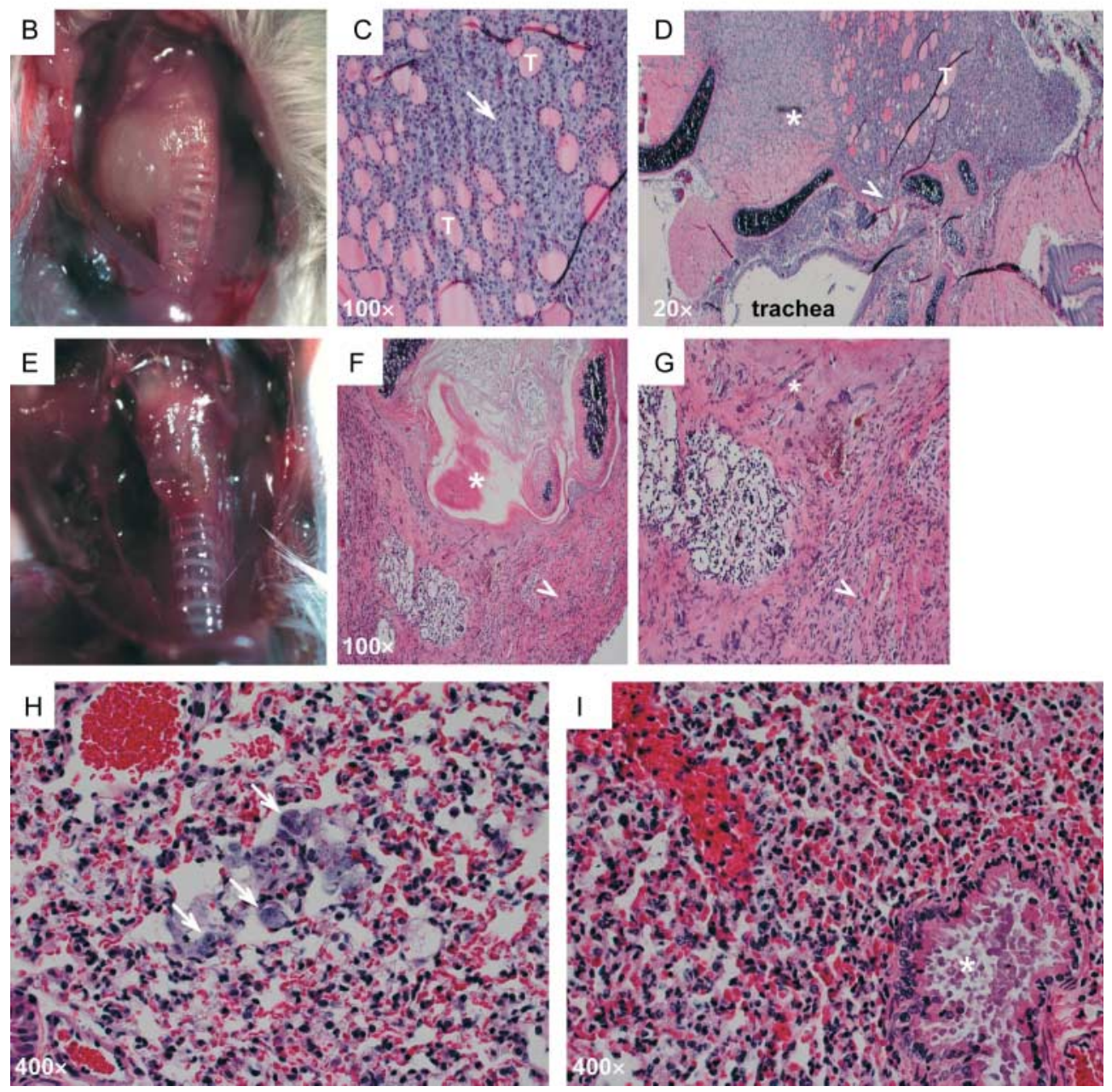

Figure 6 Thiostrepton treatment reduces ATC cell growth and metastasization in vivo. Eight mice were injected orthotopically in the right thyroid lobe with $8505 \mathrm{c}$ cells and randomly divided in two groups. Starting 7 days after orthotopic tumor implantation, mice were treated by i.p. injection of thiostrepton or vehicle twice a week for 3 weeks. (A) Thiostrepton-treated mice showed a significant decrease in thyroid tumor volume $\left(18.5 \pm 6.8 \mathrm{~mm}^{3}\right)$ compared with control mice $\left(100 \pm 19.9 \mathrm{~mm}^{3}\right)\left({ }^{\star} P<0.05\right)$. (B, C, D, E, F and G) Gross and $H \& E$ representative images of thyroids from thiostrepton-treated ( $E, F$ and $G$ ) or control $(B, C$ and $D)$ mice. In control mice, aggressive ATC (arrow) infiltrating residual thyroid follicles (T), with extra-thyroid extension into skeletal muscle (asterisk) and tracheal cartilage (arrowhead), are visible. In thiostrepton-treated mice, tumors were smaller and round shaped and had histological evidence of atrophy (arrowheads), intratracheal necrosis, and peritracheal fibrosis (asterisks). (H and I) H\&E images of lung metastases. In control mice $(\mathrm{H})$, eight to ten pleomorphic cell foci/lung sections (arrows) were counted. In thiostrepton-treated mice (I), no apparent lung metastasis was detected (asterisk: bronchus). 
cells. As shown in Supplementary (Figure 2), see section on supplementary data given at the end of this article, thiostrepton treatment reduced in a dosedependent manner FOXM1 transcriptional activity as well as its protein levels at $48 \mathrm{~h}$ of treatment. Furthermore, this led to a reduction of ATC cell viability as measured by cell count at $48 \mathrm{~h}$ (Supplementary Figure 2, see section on supplementary data given at the end of this article).

Thus, we used a recently developed orthotopic mouse model of ATC (Nucera et al. 2009). This system closely recapitulates human ATC morphology and biological behavior and allows the study of ATC cell growth into their natural environment and their metastatic properties. We injected $8505 \mathrm{c}$ cells into the right thyroid lobe of immunocompromised mice and randomly treated them twice weekly with $500 \mathrm{mg} / \mathrm{kg}$ body weight per day of thiostrepton or vehicle. Thiostrepton treatment dramatically reduced tumor volume $(P<0.05$; Fig. 6A, B and E). Thyroid tumors in vehicle-treated mice featured a highly invasive phenotype (Fig. 6C and D). In contrast, thyroid tumors in thiostrepton-treated mice showed signs of necrosis and tumor atrophy (Fig. 6F and G). Importantly, while vehicle-treated mice developed numerous metastatic foci in the lungs (Fig. $6 \mathrm{H}$ ), mice treated with thiostrepton lacked any evidence of lung metastases (Fig. 6I).

\section{Discussion}

FOXM1 oncogenic factor is a master regulator of a transcriptional program that includes genes mediating cell proliferation, motility, invasion, and metastasization. In this study, we show that FOXM1 expression is strongly upregulated in virtually all ATC samples (90\%). Recently, FOXM1 expression was reported to be negatively controlled by p53 and FOXO3a antioncogenic transcriptional factors (Barsotti \& Prives 2009, McGovern et al. 2009, Pandit et al. 2009). Impaired activity of both these tumor suppressors is part of the molecular features of ATC that, indeed, include $p 53$ loss-of-function as well as PI3K/AKT gainof-function mutations (Smallridge et al. 2009, Saji \& Ringel 2010). Here, we show that release from p53and FOXO3a-negative constraints contributes to FOXM1 upregulation in ATC cells in culture and provide immunohistochemical evidence of a correlation between AKT and p53 pathway activity and FOXM1 expression in thyroid cancer (Fig. 7). Importantly, we show that this pathway is amenable of therapeutic targeting by PI3K chemical inhibitors, drugs that have been recently proposed as potential therapeutic tools in preclinical models of thyroid cancer (Jin et al. 2009, 2011, Xing 2010, Liu et al. 2011, 2012).

FOXM1c was the FOXM1 splicing variant most abundant in ATC and FOXM1c was reported to be the form endowed with more potent mitogenic and proinvasive effects (Kim et al. 2006). We show that ATC cells depend on FOXM1 expression for both proliferation and in vitro motility and invasion. Accordingly, FOXM1 ablation downregulated the expression of a set of genes that, in turn, mediates these functions. These findings support a model whereby FOXM1 upregulation may contribute to the locally invasive, metastatic, and mitogenic phenotype of ATC; in turn, release of ATC cells from the normal cell cycle checkpoints may eventually facilitate chromosomal instability, a common feature of ATC (Fig. 7). Importantly, we could validate this model in vivo by showing that treatment with thiostrepton, a natural compound that reduces Foxml transcriptional activity and protein level (Radhakrishnan et al. 2006, Kwok et al. 2008), strongly reduced tumor burden and abolished metastasization in a thyroid orthotopic ATC mouse model. It should be noted, however, that thiostrepton may mediate these effects also by affecting targets other than FOXM1. Similarly, Ahmed et al. (2012) have previously reported that thiostrepton impairs thyroid cancer cell growth and invasion in vitro.

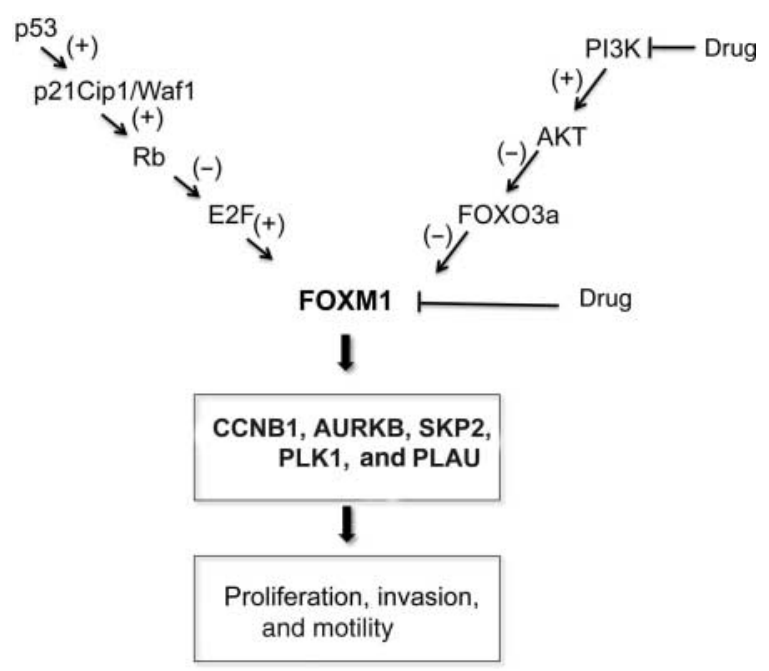

Figure 7 A model for FOXM1's role in thyroid cancer. Schematic representation of the molecular pathways linked to FOXM1 upregulation in ATC (+ and - refer to activating or inhibitory signals respectively) and gene targets whose expression is stimulated by FOXM1. This pathway can be therapeutically targeted at multiple levels; as shown here and in Ahmed et al. (2012), these levels include FOXM1 itself (thiostrepton) and PI3K (LY294002). 
Our data represent an extension of the findings recently reported by Ahmed et al. (2012), who, studying differentiated thyroid carcinomas, demonstrated that FOXM1 was upregulated in a fraction (28.4\%) of PTCs and correlated with aggressive PTC variants (tall-cell) and expression of molecular markers of invasiveness, such as metalloproteases. Here, we show that FOXM1 is significantly increased in ATCs compared with WDTCs (PTCs and/or FTCs) and PDCs, and when considering only the most aggressive thyroid cancer phenotypes (PDCs and ATCs), high and/or moderate levels of FOXM1 were significantly associated with ATCs. Moreover, by studying a selected series of PTC with or without tumor and/or thyroid capsule invasion, we found that FOXM1 levels correlated with a tumor invasive phenotype.

Altogether, these findings suggest that FOXM1 is a molecular determinant of thyroid cancer malignant phenotype and may be exploited as a molecular marker of aggressiveness as well as a molecular target in approaches aimed at inhibiting directly its transcriptional activity or indirectly the pathways sustaining its expression (Fig. 7).

\section{Supplementary data}

This is linked to the online version of the paper at http://dx. doi.org/10.1530/ERC-12-0031.

\section{Declaration of interest}

The authors declare that there is no conflict of interest that could be perceived as prejudicing the impartiality of the research reported.

\section{Funding}

This study was supported by the Associazione Italiana per la Ricerca sul Cancro (AIRC), the Ministero dell'Università e della Ricerca (MiUR), and by the grant MERIT of MIUR. G Garcia-Rostan is supported by Programa Ramón y Cajal, Ministerio de Ciencia e Innovación, Social EU Funds, Universidad de Valladolid, Spain. C Nucera (Principal Investigator, Program: Human Thyroid Cancers Preclinical and Translational Research) was funded by the NIHR21CA165039-01A1 and the American Thyroid Association for Thyroid Cancer Research.

\section{Acknowledgements}

The authors thank F Curcio for the P5 cells, K M Yao for the FOXM1c-HA plasmid, M Crescenzi for E2F4, and R H Costa for the 6XCDX2 reporter plasmid. They also thank $\mathrm{N}$ E Heldin and N Onoda for providing ATC cells. They are also grateful to Drs J Cameselle-Teijeiro, X Matías-Guiu, A Herrero, and M Fresno - Forcelledo for providing human
PDC and ATC samples. They thank M Zheng (Brigham and Women's Hospital), N Hu (Beth Israel Deaconess Medical Center), and C Nardella (Beth Israel Deaconess Medical Center) for technical assistance.

\section{References}

Ahmad A, Wang Z, Kong D, Ali S, Li Y, Banerjee S, Ali R \& Sarkar FH 2010 FoxM1 down-regulation leads to inhibition of proliferation, migration and invasion of breast cancer cells through modulation of extra-cellular matrix degrading factors. Breast Cancer Research and Treatment 122 337-346. (doi:10.1007/s10549-009-0572-1)

Ahmed M, Uddin S, Hussain AR, Alyan A, Jehan Z, Al-Dayel F, Al-Nuaim A, Al-Sobhi S, Amin T, Bavi P et al. 2012 FoxM1 and its association with matrix metalloproteinases (MMP) signaling pathway in papillary thyroid carcinoma. Journal of Clinical Endocrinology and Metabolism 97 E1-E13. (doi:10.1210/jc.2011-1506)

Barsotti AM \& Prives C 2009 Pro-proliferative FoxM1 is a target of p53-mediated repression. Oncogene $\mathbf{2 8}$ 4295-4305. (doi:10.1038/onc.2009.282)

Bhat UG, Halasi M \& Gartel AL 2009 Thiazole antibiotics target FoxM1 and induce apoptosis in human cancer cells. PLoS ONE 4 e5592. (doi:10.1371/journal.pone.0005592)

Chiappetta G, De Marco C, Quintiero A, Califano D, Gherardi S, Malanga D, Scrima M, Montero-Conde C, Cito L, Monaco M et al. 2007 Overexpression of the $\mathrm{S}$-phase kinase-associated protein 2 in thyroid cancer. Endocrine-Related Cancer 14 405-420. (doi:10.1677/ ERC-06-0030)

Curcio F, Ambesi-Impiombato FS, Perrella G \& Coon HG 1994 Long-term culture and functional characterization of follicular cells form adult normal human thyroids. PNAS 9 9004-9008. (doi:10.1073/pnas.91.19.9004)

Frisk T, Foukakis T, Dwight T, Lundberg J, Höög A, Wallin G, Eng C, Zedenius J \& Larsson C 2002 Silencing of the PTEN tumor-suppressor gene in anaplastic thyroid cancer. Genes, Chromosomes \& Cancer 35 74-80. (doi:10.1002/gcc.10098)

Garcia-Rostan G \& Sobrinho-Simoes M 2011 Poorly differentiated thyroid carcinoma: an evolving entity. Diagnostic Histopathology 17 114-123. (doi:10.1016/j. mpdhp.2010.12.001)

Garcia-Rostan G, Zhao H, Camp RL, Pollan M, Herrero A, Pardo J, Wu R, Carcangiu ML, Costa J \& Tallini G 2003 Ras mutations are associated with aggressive tumor phenotypes and poor prognosis in thyroid cancer. Journal of Clinical Oncology 21 3226-3235. (doi:10.1200/JCO.2003.10.130)

Garcia-Rostan G, Costa AM, Pereira-Castro I, Salvatore G, Hernandez R, Hermsem MJ, Herrero A, Fusco A, Cameselle-Teijeiro J \& Santoro M 2005 Mutation of the PIK3CA gene in anaplastic thyroid carcinoma. Cancer Research 15 10199-10207. (doi:10.1158/0008-5472. CAN-04-4259) 
Gimm O, Perren A, Weng LP, Marsh DJ, Yeh JJ, Ziebold U, Gil E, Hinze R, Delbridge L, Lees JA et al. 2000 Differential nuclear and cytoplasmic expression of PTEN in normal thyroid tissue, and benign and malignant epithelial thyroid tumors. American Journal of Pathology 156 1693-1700. (doi:10.1016/S0002-9440(10)65040-7)

Halasi M \& Gartel AL 2009 A novel mode of FoxM1 regulation: positive auto-regulatory loop. Cell Cycle 8 1966-1967. (doi:10.4161/cc.8.12.8708)

Hedinger C, Williams ED \& Sobin LH 1989 The WHO histological classification of thyroid tumors: a commentary on the second edition. Cancer 63 908-911. (doi:10.1002/1097-0142(19890301)63:5<908::AIDCNCR2820630520 > 3.0.CO;2-I)

Hegde NS, Sanders DA, Rodrigez R \& Balasubramanian S 2011 The transcription factor FOXM1 is a cellular target of the natural product thiostrepton. Nature Chemistry 3 725-731. (doi:10.1038/nchem.1114)

Ito Y, Yoshida H, Nakano K, Takamura Y, Kobayashi K, Yokozawa T, Matsuzuka F, Matsuura N, Kuma K \& Miyauchi A 2002 Expression of G2-M modulators in thyroid neoplasms: correlation of cyclin A, B1 and cdc2 with differentiation. Pathology, Research and Practice 198 397-402. (doi:10.1078/0344-0338-00272)

Jin N, Jiang T, Rosen DM, Nelkin BD \& Ball DW 2009 Dual inhibition of mitogen-activated protein kinase kinase and mammalian target of rapamycin in differentiated and anaplastic thyroid cancer. Journal of Clinical Endocrinology and Metabolism 94 4107-4112. (doi:10. 1210/jc.2009-0662)

Jin N, Jiang T, Rosen DM, Nelkin BD \& Ball DW 2011 Synergistic action of a RAF inhibitor and a dual $\mathrm{PI} 3 \mathrm{~K} / \mathrm{mTOR}$ inhibitor in thyroid cancer. Clinical Cancer Research: an Official Journal of the American Association for Cancer Research 17 6482-6489. (doi:10. 1158/1078-0432.CCR-11-0933)

Kalin TV, Wang IC, Ackerson TJ, Major ML, Detrisac CJ, Kalinichenko VV, Lyubimov A \& Costa RH 2006 Increased levels of the FoxM1 transcription factor accelerate development and progression of prostate carcinomas in both TRAMP and LADY transgenic mice. Cancer Research 66 1712-1720. (doi:10.1158/00085472.CAN-05-3138)

Kalinichenko VV, Major ML, Wang X, Petrovic V, Kuechle J, Yoder HM, Dennewitz MB, Shin B, Datta A, Raychaudhuri P et al. 2004 Foxm1b transcription factor is essential for development of hepatocellular carcinomas and is negatively regulated by the p19ARF tumor suppressor. Genes and Development 18 830-850. (doi:10.1101/gad.1200704)

Kim IM, Ackerson T, Ramakrishna S, Tretiakova M, Wang IC, Kalin TV, Major ML, Gusarova GA, Yoder HM, Costa RH et al. 2006 The forkhead box m1 transcription factor stimulates the proliferation of tumor cells during development of lung cancer. Cancer Research 66 2153-2161. (doi:10.1158/0008-5472.CAN05-3003)
Kondo T, Ezzat S \& Asa SL 2006 Pathogenetic mechanisms in thyroid follicular-cell neoplasia. Nature Reviews. Cancer 6 292-306. (doi:10.1038/nrc1836)

Korver W, Roose J \& Clevers H 1997 The winged-helix transcription factor Trident is expressed in cycling cells. Nucleic Acids Research 25 1715-1719. (doi:10.1093/nar/ 25.9.1715)

Kwok JM, Myatt SS, Marson CM, Coombes RC, Constantinidou D \& Lam EW 2008 Thiostrepton selectively targets breast cancer cells through inhibition of FOXM1 expression. Molecular Cancer Therapeutics 7 2022-2032. (doi:10.1158/1535-7163.MCT-08-0188)

Laoukili J, Kooistra MR, Bràs A, Kauw J, Kerkhoven RM, Morrison A, Clevers H \& Medema RH 2005 FoxM1 is required for execution of the mitotic programme and chromosomal stability. Nature Cell Biology 7 126-136. (doi:10.1038/ncb1217)

Li Q, Zhang N, Jia Z, Le X, Dai B, Wei D, Huang S, Tan D \& Xie K 2009 Critical role and regulation of transcription factor FoxM1 in human gastric cancer angiogenesis and progression. Cancer Research 69 3501-3509. (doi:10.1158/0008-5472.CAN-08-3045)

Liu M, Dai B, Kang SH, Ban K, Huang FJ, Lang FF, Aldape KD, Xie TX, Pelloski CE, Xie K et al. 2006 FoxM1B is overexpressed in human glioblastomas and critically regulates the tumorigenicity of glioma cells. Cancer Research 66 3593-3602. (doi:10.1158/0008-5472.CAN05-2912)

Liu R, Liu D, Trink E, Bojdani E, Ning G \& Xing M 2011 The Akt-specific inhibitor MK2206 selectively inhibits thyroid cancer cells harboring mutations that can activate the PI3K/Akt pathway. Journal of Clinical Endocrinology and Metabolism 96 E577-E585. (doi:10.1210/jc. 2010-2644)

Liu R, Liu D \& Xing M 2012 The Akt Inhibitor MK2206 synergizes, but perifosine antagonizes, the BRAFV600E inhibitor PLX4032 and the MEK1/2 inhibitor AZD6244 in the inhibition of thyroid cancer cells. Journal of Clinical Endocrinology and Metabolism 97 E173-E182. (doi:10.1210/jc.2011-1054)

McGovern UB, Francis RE, Peck B, Guest SK, Wang J, Myatt SS, Krol J, Kwok JM, Polychronis A, Coombes RC et al. 2009 Gefitinib (Iressa) represses FOXM1 expression via FOXO3a in breast cancer. Molecular Cancer Therapeutics 8 582-591. (doi:10.1158/1535-7163.MCT08-0805)

Miller KA, Yeager N, Baker K, Liao XH, Refetoff S \& Di Cristofano A 2009 Oncogenic Kras requires simultaneous PI3K signaling to induce ERK activation and transform thyroid epithelial cells in vivo. Cancer Research 69 3689-3694. (doi:10.1158/0008-5472.CAN09-0024)

Nappi TC, Salerno P, Zitzelsberger H, Carlomagno F, Salvatore G \& Santoro M 2009 Identification of Polo-like kinase 1 as a potential therapeutic target in anaplastic thyroid carcinoma. Cancer Research 69 1916-2223. (doi:10.1158/0008-5472.CAN-08-1693) 
Nikiforov YE \& Nikiforova MN 2011 Molecular genetics and diagnosis of thyroid cancer. Nature Reviews. Endocrinology 7 569-580. (doi:10.1038/nrendo. 2011.142)

Nikiforova MN, Kimura ET, Gandhi M, Biddinger PW, Knauf JA, Basolo F, Zhu Z, Giannini R, Salvatore G, Fusco A et al. 2003 BRAF mutations in thyroid tumors are restricted to papillary carcinomas and anaplastic or poorly differentiated carcinomas arising from papillary carcinomas. Journal of Clinical Endocrinology and Metabolism 88 5399-5404. (doi:10.1210/jc.2003-030838)

Nucera C, Nehs MA, Mekel M, Zhang X, Hodin R, Lawler J, Nose V \& Parangi S 2009 A novel orthotopic mouse model of human anaplastic thyroid carcinoma. Thyroid 19 1077-1084. (doi:10.1089/thy.2009.0055)

Nucera C, Porrello A, Antonello ZA, Mekel M, Nehs MA, Giordano TJ, Gerald D, Benjamin LE, Priolo C, Puxeddu E et al. 2010 B-Raf(V600E) and thrombospondin-1 promote thyroid cancer progression. PNAS 107 10649-10654. (doi:10.1073/pnas.1004934107)

Nucera C, Nehs MA, Nagarkatti SS, Sadow PM, Mekel M, Fischer AH, Lin PS, Bollag GE, Lawler J, Hodin RA et al. 2011 Targeting BRAFV600E with PLX4720 displays potent antimigratory and anti-invasive activity in preclinical models of human thyroid cancer. Oncologist 16 296-309. (doi:10.1634/theoncologist.2010-0317)

Pandit B, Halasi M \& Gartel AL 2009 p53 negatively regulates expression of FOXM1. Cell Cycle 8 3425-3427. (doi:10.4161/cc.8.20.9628)

Radhakrishnan SK, Bhat UG, Hughes DE, Wang IC, Costa RH \& Gartel AL 2006 Identification of a chemical inhibitor of the oncogenic transcription factor forkhead box M1. Cancer Research 66 9731-9735. (doi:10.1158/ 0008-5472.CAN-06-1576)

Raychaudhuri P \& Park HJ 2011 FoxM1: a master regulator of tumor metastasis. Cancer Research 71 4329-4333. (doi:10.1158/0008-5472.CAN-11-0640)

Ricarte-Filho JC, Ryder M, Chitale DA, Rivera M, Heguy A, Ladanyi M, Janakiraman M, Solit D, Knauf JA, Tuttle RM et al. 2009 Mutational profile of advanced primary and metastatic radioactive iodine-refractory thyroid cancers reveals distinct pathogenetic roles for BRAF, PIK3CA, and AKT1. Cancer Research 69 4885-4893. (doi:10.1158/0008-5472.CAN-09-0727)

Saji M \& Ringel MD 2010 The PI3K-Akt-mTOR pathway in initiation and progression of thyroid tumors. Molecular and Cellular Endocrinology 321 20-28. (doi:10.1016/j. mce.2009.10.016)

Salvatore G, Nappi TC, Salerno P, Jiang Y, Garbi C, Ugolini C, Miccoli P, Basolo F, Castellone MD, Cirafici AM et al. 2007 A cell proliferation and chromosomal instability signature in anaplastic thyroid carcinoma. Cancer Research 67 10148-10158. (doi:10.1158/00085472.CAN-07-1887)

Santarpia L, El-Naggar AK, Cote GJ, Myers JN \& Sherman SI 2008 Phosphatidylinositol 3-kinase/akt and ras/rafmitogen-activated protein kinase pathway mutations in anaplastic thyroid cancer. Journal of Clinical Endocrinology and Metabolism 93 278-284. (doi:10.1210/jc. 2007-1076)

Schweppe RE, Klopper JP, Korch C, Pugazhenthi U, Benezra M, Knauf JA, Fagin JA, Marlow LA, Copland JA, Smallridge RC et al. 2008 Deoxyribonucleic acid profiling analysis of 40 human thyroid cancer cell lines reveals cross-contamination resulting in cell line redundancy and misidentification. Journal of Clinical Endocrinology and Metabolism 93 4331-4341. (doi:10.1210/jc.2008-1102)

Smallridge RC, Marlow LA \& Copland JA 2009 Anaplastic thyroid cancer: molecular pathogenesis and emerging therapies. Endocrine-Related Cancer 16 17-44. (doi:10.1677/ERC-08-0154)

Sorrentino R, Libertini S, Pallante PL, Troncone G, Palombini L, Bavetsias V, Spalletti-Cernia D, Laccetti P, Linardopoulos S, Chieffi P et al. 2005 Aurora B overexpression associates with the thyroid carcinoma undifferentiated phenotype and is required for thyroid carcinoma cell proliferation. Journal of Clinical Endocrinology and Metabolism 90 928-935. (doi:10.1210/jc. 2004-1518)

Teh MT, Wong ST, Neill GW, Ghali LR, Philpott MP \& Quinn AG 2002 FOXM1 is a downstream target of Gli1 in basal cell carcinomas. Cancer Research 62 4773-4780.

Volante M, Collini P, Nikiforov YE, Sakamoto A, Kakudo K, Katoh R, Lloyd RV, LiVolsi VA, Papotti M, Sobrinho-Simoes M et al. 2007 Poorly differentiated thyroid carcinoma: the Turin proposal for the use of uniform diagnostic criteria and an algorithmic diagnostic approach. American Journal of Surgical Pathology 31 1256-1264. (doi:10.1097/PAS.0b013e3180309e6a)

Wang Z, Banerjee S, Kong D, Li Y \& Sarkar FH 2007 Downregulation of forkhead box M1 transcription factor leads to the inhibition of invasion and angiogenesis of pancreatic cancer cells. Cancer Research 67 8293-8300. (doi:10.1158/0008-5472.CAN-07-1265)

Wiseman SM, Masoudi H, Niblock P, Turbin D, Rajput A, Hay J, Bugis S, Filipenko D, Huntsman D \& Gilks B 2007 Anaplastic thyroid carcinoma: expression profile of targets for therapy offers new insights for disease treatment. Annals of Surgical Oncology 14 719-729. (doi:10.1245/s10434-006-9178-6)

Wonsey DR \& Follettie MT 2005 Loss of the forkhead transcription factor FoxM1 causes centrosome amplification and mitotic catastrophe. Cancer Research $\mathbf{6 5}$ 5181-5189. (doi:10.1158/0008-5472.CAN-04-4059)

Wreesmann VB, Ghossein RA, Patel SG, Harris CP, Schnaser EA, Shaha AR, Tuttle RM, Shah JP, Rao PH \& Singh B 2002 Genome-wide appraisal of thyroid cancer progression. American Journal of Pathology 161 1549-1556. (doi:10.1016/S0002-9440(10)64433-1)

Wu G, Mambo E, Guo Z, Hu S, Huang X, Gollin SM, Trink B, Ladenson PW, Sidransky D \& Xing M 2005 Uncommon mutation, but common amplifications, of the 
PIK3CA gene in thyroid tumors. Journal of Clinical Endocrinology and Metabolism 90 4688-4693. (doi:10. 1210/jc.2004-2281)

Xing M 2010 Genetic alterations in the phosphatidylinositol3 kinase/Akt pathway in thyroid cancer. Thyroid 20 697-706. (doi:10.1089/thy.2010.1646)

Ye H, Kelly TF, Samadani U, Lim L, Rubio S, Overdier DG, Roebuck KA \& Costa RH 1997 Hepatocyte nuclear factor 3/fork head homolog 11 is expressed in proliferating epithelial and mesenchimal cells of embryonic and adult tissues. Molecular and Cellular Biology 17 31626-31641.

Received in final form 17 August 2012 Accepted 21 August 2012

Made available online as an Accepted Preprint 23 August 2012 